\title{
Overexpression of Pim-1 in bladder cancer
}

\author{
Shengjie Guo ${ }^{1 \dagger}$, Xiaopeng Mao ${ }^{1 \dagger}$, Junxing Chen ${ }^{1}$, Bin Huang ${ }^{1}$, Chu Jin²,3, Zhenbo Xu ${ }^{2,4}$, Shaopeng Qiu ${ }^{1 *}$
}

\begin{abstract}
Background: Pim-1 is a serine-threonine kinase which promotes early transformation, cell proliferation and cell survival during tumorigenesis. Several studies have demonstrated that Pim-1 kinase play a role in different cancer types, however, the function of Pim-1 in bladder cancer is poorly understood.

Methods: Expression and localization of Pim-1 in human normal and malignant bladder specimens were examined by Immunohistochemistry and Pim-1 staining score was compared with several clinicopathologic parameters. To further demonstrate the biological function of Pim-1 in bladder cancer, its expression was validated in five bladder cancer cell lines by western blot and immunohistochemistry analyses. Subsequent knockdown of Pim-1 was achieved by lentivirus encoding small interfering RNA, and the effect of Pim-1 on bladder cell survival and drug sensitivity were further assessed by colony formation and cell proliferation assays.

Results: When compared with normal epithelium, Pim-1 was overexpressed in bladder cancer epithelium, and the expression level was higher in invasive bladder cancer than Non-invasive bladder cancer specimens. Pim-1 was also detected in all the bladder cancer cell lines examined in our study. Moreover, the knockdown of Pim-1 significantly inhibited bladder cancer cell growth and also sensitized cells to chemotherapeutic drugs in vitro.

Conclusions: Our results in this study suggest that Pim-1 may play a role in bladder cancer initiation and progression. Since Pim-1 is also involved in bladder cancer cell survival and drug resistance, Pim-1 is a potential candidate for targeted therapy in bladder cancer.
\end{abstract}

\section{Background}

Bladder cancer is one of the most common types of cancer globally, with approximately $75 \%$ of the diagnosed tumors classified as Non-invasive tumor (Ta, Tis, or T1). Treatment of Non-invasive tumor includes transurethral resection (TUR) with or without intravesical instillation therapy, but the recurrence rate is high, ranging from $50 \%$ to $70 \%$. In addition, an average of $10 \%$ to $20 \%$ for Non-invasive tumors may further progress to muscle-invasive disease, thus lead to eventual radical Cystectomy and urinary diversion [1-3]. In this context, clinicians face challenges to identify the novel therapeutic targets for bladder cancer.

Pim-1 is overexpressed in several types of cancer, including lymphoid and haematopoietic malignancies [4], prostate cancer [5], squamous cell carcinomas [6], gastric carcinoma and colorectal carcinomas [7].

\footnotetext{
* Correspondence: qiusp2009@live.cn

+ Contributed equally

'Department of Urology, the First Affiliated Hospital, Sun Yat-Sen University,

Guangzhou, 510080 China

Full list of author information is available at the end of the article
}

Currently available studies have demonstrated that the expression of Pim-1 can be predictive of tumor outcome following chemotherapy and surgery, and it is correlated with the enhanced metastatic potential of the tumor [8]. As a member of serine/threonine kinase family, Pim-1 has multiple roles in tumorigenesis such as promoting transformation and cell proliferation partly through regulation of cell cycle and transcription by phosphorylating of number of substrates including cdc25A/C, HP1, and p100 [9-11]. Moreover, it has been shown that Pim1 may play a role in the regulation of the survival signaling through the modulation of Bcl-2 family member including Bad, Bcl-2 and Bcl-XL [12-14]. However, the expression and significance of Pim-1 in bladder cancer remains unknown. Therefore, the aims of the present study are to investigate the expression level of Pim-1 in bladder cancer tissue and study its function in the pathogenesis and progression of bladder cancer.
C Biomed Central

C 2010 Guo et al; licensee BioMed Central Ltd. This is an Open Access article distributed under the terms of the Creative Commons Attribution License (http://creativecommons.org/licenses/by/2.0), which permits unrestricted use, distribution, and reproduction in any medium, provided the original work is properly cited. 


\section{Methods}

\section{Patient samples}

Sixty-six clinical bladder samples isolated from the First Affiliated Hospital of the Sun Yat-Sen University (Guangzhou, China), were examined in the present study. All patients including forty-eight men (72.3\%) and eighteen women $(27.7 \%)$, had been treated for urothelial carcinoma of the bladder by transurethral resection of bladder (TUR) or Cystectomy and were diagnosed with a bladder cancer for the first time at an average age of 56 years (range, 33-78 years). Pathologic staging and grading were performed according to the 2002 TNM classification system and World Health Organization criteria, respectively. The use of the human tissue in this study was approved by the Ethics Council of the Sun Yat-Sen University for Approval of Research Involving Human Subjects.

\section{Immunohistochemistry}

All $5 \mu \mathrm{m}$ thick paraffin sections were deparaffinized with xylene and rehydrated through graded alcohol washes, followed by antigen retrieval by heating sections in sodium citrate buffer $(10 \mathrm{mmol} / \mathrm{L}, \mathrm{pH}$ 6.0) for 30 minutes. Endogenous peroxidase activity was blocked with 30 min incubation in $0.03 \% \mathrm{H}_{2} \mathrm{O}_{2}$ in methanol. The slides were then blocked by incubation in normal goat serum (dilution 1:10) in PBS ( $\mathrm{pH} 7.4$ ) and subsequently incubated for monoclonal mouse IgG1 anti-Pim-1 antibody(sc-13513; Santa Cruz Biotechnology, Santa Cruz, CA, USA) with 1:30 dilution at $4^{\circ} \mathrm{C}$ overnight. Following this step, slides were treated with biotin-labeled anti-IgG and incubated with preformed avidin-biotin peroxidase complex. Control staining of the same sections was performed with the preimmune primary antibody, and no Pim-1 immunostaining was observed in these sections. The sections were briefly counter-stained with hematoxylin. IHC reactions for all samples were repeated at least three times, and typical results were illustrated.

\section{Scoring and Statistical analyses}

The staining of Pim-1 was graded in each sample based on the intensity of the immunoreactivity in the cancer cells and was stratified as strong staining (3), moderate staining (2), weak staining (1) and negative (0). Using these criteria, the immunostaining results were evaluated independently by XPM and $\mathrm{BH}$. The correlation of interobserver was calculated from the independent evaluations. For cases with discrepancy, a consensus was reached during a common evaluation session. The statistical analyses were carried out by using SAS version 9.0 statistics software (SAS Institute, Inc., Cary, NC).

\section{Cell culture and lentiviral infection}

Bladder cancer cell lines T24, UM-UC-3, 5637, J82 and RT-4 were purchased from the American Type Culture Collection. UM-UC-3 and T24 cells were grown in Dulbecco's modified Eagle's medium. 5637, J82 and RT-4 cells were maintained in RPMI 1640 with $10 \%$ fetal bovine serum and $1 \%(\mathrm{v} / \mathrm{v})$ penicillin and streptomycin $(100 \mu \mathrm{g} / \mathrm{ml})$ and maintained at $37^{\circ} \mathrm{C}$ in a $5 \% \mathrm{CO}_{2}$ atmosphere. The infection of lentivirus of Pim-1 siRNA was carried out as reported previously [15].

\section{Western Blot}

Western blot was performed as described previously [16]. Briefly, the equal amounts of sample were resolved on a SDS polyacrylamide gel and transferred to a polyvinylidene difluoride membrane. Blots were incubated with the indicated primary antibodies overnight at $4^{\circ} \mathrm{C}$ and followed by detection with horseradish peroxidaseconjugated secondary antibody. The monoclonal antiPim-1 antibody was used at the dilution of 1:300, whereas anti-tubulin, Bcl-2, Bad and p-Bad (Ser112) (Santa Cruz Biotechnology, Santa Cruz, CA, USA) were used at the dilution of 1:2,000.

\section{Cell immunoperoxidase staining}

Bladder cancer cells were plated onto the glass slides. After $24 \mathrm{~h}$, cells were fixed with ice-cold acetone. The endogenous peroxides activity was inactivated by incubating cells with $0.03 \% \mathrm{H}_{2} \mathrm{O}_{2}$ for $10 \mathrm{~min}$. Slides were then incubated with Pim-1 antibody at room temperature for 1 hour and followed by horseradish peroxidesconjugated anti-mouse Ig (Chemicon; 1:500 dilutions). Finally, slides were incubated with biotin-labeled antiIgG avidin-biotin peroxidase complex and developed with DAB Solution.

\section{Colony formation assay}

The cells $\left(1 \times 10^{4}\right)$ were seeded in 6 -well plate and infected with the lentivirus expressing control siRNA or Pim-1 siRNA. Cell culture was maintained in complete medium for two weeks. The cell colonies were then visualized by Coomassie blue staining.

\section{Drug-sensitivity assay}

Cells were infected with lentivirus encoding control siRNA or Pim-1 siRNA. At $48 \mathrm{~h}$ post-infection, cells were seeded on 96-well plate at a density of $6 \times 10^{3}$ cells/well. After $24 \mathrm{~h}$, cells were treated with various doses of Doxorubicin or Docetaxel (Sigma, St Louis, MO, USA) for another $48 \mathrm{~h}$. The cells viability was measured by the WST-1 (Roche) assay following the manufacturer's instructions. 


\section{Results}

\section{Overexpression of Pim-1 in human bladder cancer specimens}

To validate the expression of Pim-1 protein in bladder cancer, human bladder specimens containing normal epithelium ( $n=21)$ and malignant tissues $(n=45)$ were studied by immunohistochemistry using Pim-1 antibody. The staining data showed that Pim-1 expression is weakely detect in the epithelial cells of normal bladder epithelium, however, most of the malignant bladder epithelial cells exhibited Pim-1 immunoreactivity in both cytoplasm and nuclear (Figure 1). For further analysis, the immunoreactivity of Pim-1 was divided into negative (score 0-1) vs. positive (score $2-3)$ subgroups. Detailed staining scores in normal and malignant bladder specimens are presented in Table 1, which showed that Pim-1 expression is significantly higher in bladder cancer specimens $(84.4 \%)$ than in normal specimens $(9.5 \%)(\mathrm{p}<0.001)$, suggesting an overexpression of Pim-1 at the translational level in bladder cancer.

To explore potential correlations between the expression of Pim-1 and tumor progression, malignant bladder specimens were further classified into Noninvasive (Tis, Ta and $\mathrm{T} 1$ ) and invasive ( $\geq \mathrm{T} 2$ ) groups. The data (Table 2) shows that the staining intensity of Pim-1 is increased in invasive bladder carcinoma samples (95\%) when compared with Non-invasive bladder cancer specimens $(76 \%)(\mathrm{p}<0.01)$. However,
Table 1 Pim-1 immunostaining intensity in human normal and maligancy bladder tissues

\begin{tabular}{lccc}
\hline groups & $\mathbf{n}$ & negtive & positive \\
\hline Normal & 21 & $19(90.5 \%)$ & $2(9.5 \%)$ \\
Malignancy & 45 & $7(15.6 \%)$ & $38(84.4 \%)$ \\
\hline
\end{tabular}

$p<0.001$

correlation of Pim-1 within different tumor grades was not observed (data not shown). Taken together, Pim-1 may be associated with bladder cancer initiation and progression.

\section{Expression profile of Pim-1 in bladder cancer cell lines}

In order to further demonstrate the role and function of Pim-1 in bladder cancer, the expression level of Pim-1 was validated in bladder cancer cell lines using western blot. As shown in Figure 2A, Pim-1 is expressed in all five bladder cancer cell lines at variable levels, with the maximum level in highly invasive cancer cell lines T24 and UM-UC-3.

The localization of Pim-1 in bladder cancer cells was confirmed by immunoperoxidase staining and as the results showed that Pim-1 was detected in all human bladder cell lines examined, including T24, UM-UC-3, 5637, J82 and RT-4. Representative images are presented in Figure 2B. The positive signals were primarily immunolocalized in both cell cytoplasm and nucleus, while some cell membrane staining is also detected.
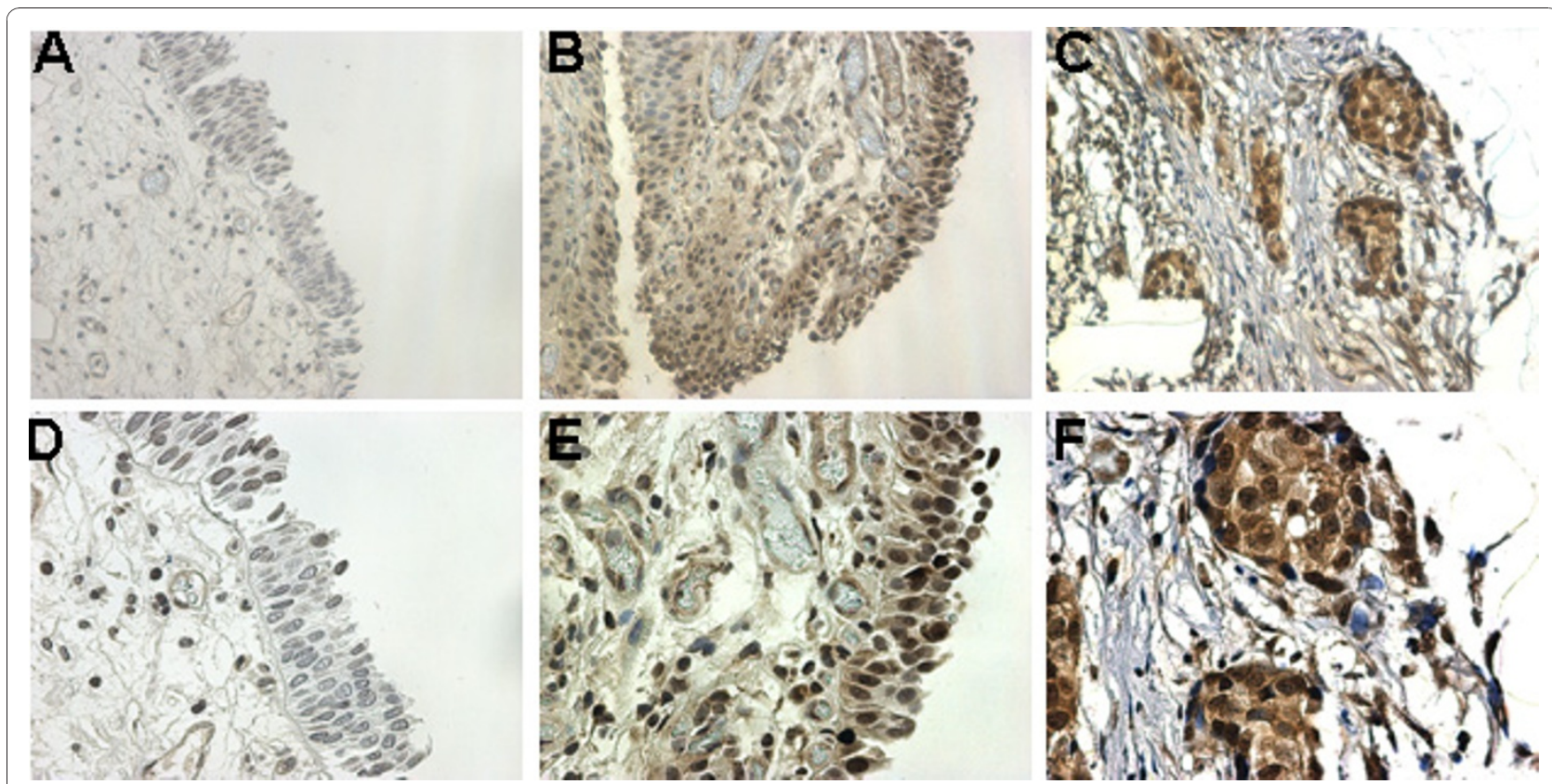

Figure 1 Overexpression of Pim-1 in human bladder cancer specimens. Pim-1 is overexpressed in both cytoplasm and nucleus of bladder cancer cells. Normal bladder epithelium cells show no or minimal staining (A\&D). Bladder cancer cells show cytoplasm and nucleus positive staining (B\&E). Invasive bladder cancer cells show strong staining(C\&F). Magnification $\times 200(A, B, C)$, or $\times 400(D, E, F)$. 
Table 2 Pim-1 immunostaining intensity in No-invasive and Invasive bladder tumors

\begin{tabular}{lccc}
\hline groups & $\mathbf{n}$ & negtive & positive \\
\hline Non-invasive & 25 & $6(24.0 \%)$ & $19(76.0 \%)$ \\
Invasive & 20 & $1(5 \%)$ & $19(95.0 \%)$ \\
\hline$p<0.01$ & & &
\end{tabular}

$p<0.01$

\section{Pim-1 is essential for bladder cancer cell survival}

To examine the biological significance of Pim-1, targeted knockdown of Pim-1 was achieved by lentivirus encoding siRNA specific for Pim-1 in T24 and UM-UC-3 cells, which express relatively high levels of Pim-1. The Pim-1 siRNA using in our experiments has been previously shown to specific knockdown Pim-1 in multiple prostate cancer cell lines $[17,18]$. As shown in Figure 3A, downregulation of Pim-1 decreased Phospho-Bad and Bcl-2 levels that are known to be regulated by Pim-1. Furthermore, downregulation of Pim-1 could also inhibit the cell growth and proliferation in vitro (Figure $3 \mathrm{~B}$ ), suggesting that Pim-1 may be important for the growth and survival of bladder cancer cells.

\section{Knockdown of Pim-1 sensitizes bladder cancer cells to chemotherapy in vitro}

As Pim-1 is involved in drug resistance in some cancer types and adjuvant intravesical chemotherapy is one of the most common treatments in bladder cancer, we tested whether Pim-1 is also involved in drug response of bladder cancer cells. T24 and UM-UC-3 cells were treated with lentivirus encoding the siRNA specific for vector control or Pim-1 and then were tested for their responses to chemotherapeutic drugs. As shown in Figure 3C, downregulation of Pim-1 sensitized T24 and UM-UC-3 cells to Doxorubicin (DOX) and Docetaxel (DTX) when compared to the vector control. Our data implied that Pim-1 may contribute to the resistance of apoptosis and survival of bladder cancer cells in response to cytotoxic drugs.

\section{Discussion}

In the present study we demonstrated for the first time that, Pim-1 was increased in human bladder cancer epithelium as compared with that in normal bladder tissue. When the tumors were stratified by Non-invasive and invasive, a statistically significant increase of Pim-1 expression was found in the subgroup of invasive tumor when compared with that in the Non-invasive tumor. Pim-1 was also detected in all human bladder cancer cell lines tested in our study. Knockdown Pim-1 led to decreased phosphorylation of Bad and reduced expression of Bcl-2. Furthermore, downregulation of Pim-1 inhibited the bladder cancer cells growth and sensitized them to chemotherapy in vitro. Further evaluation of the prognostic significance of Pim-1 in a larger cohort with sufficient follow-up times will allow better understand of the clinical significance of Pim-1.

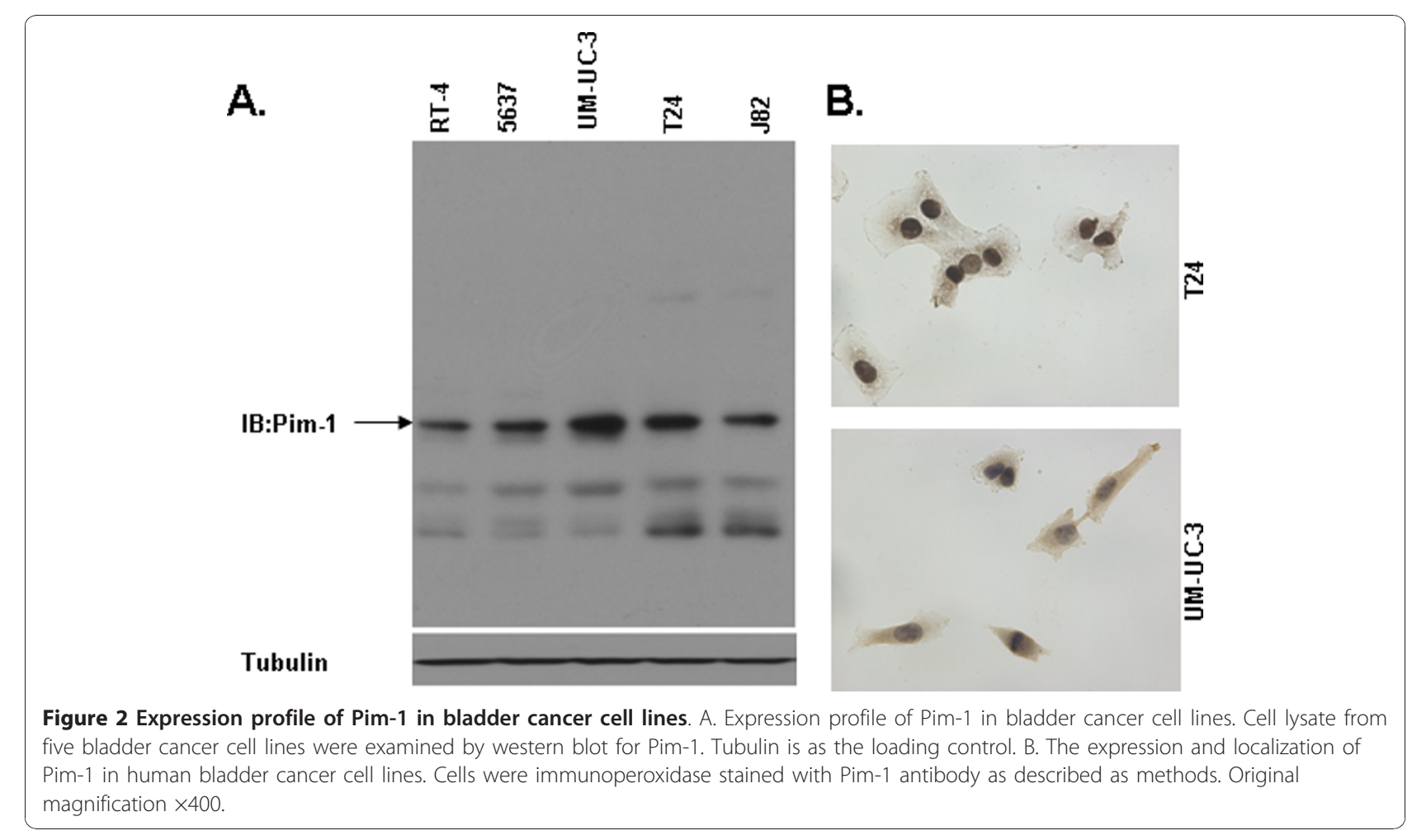




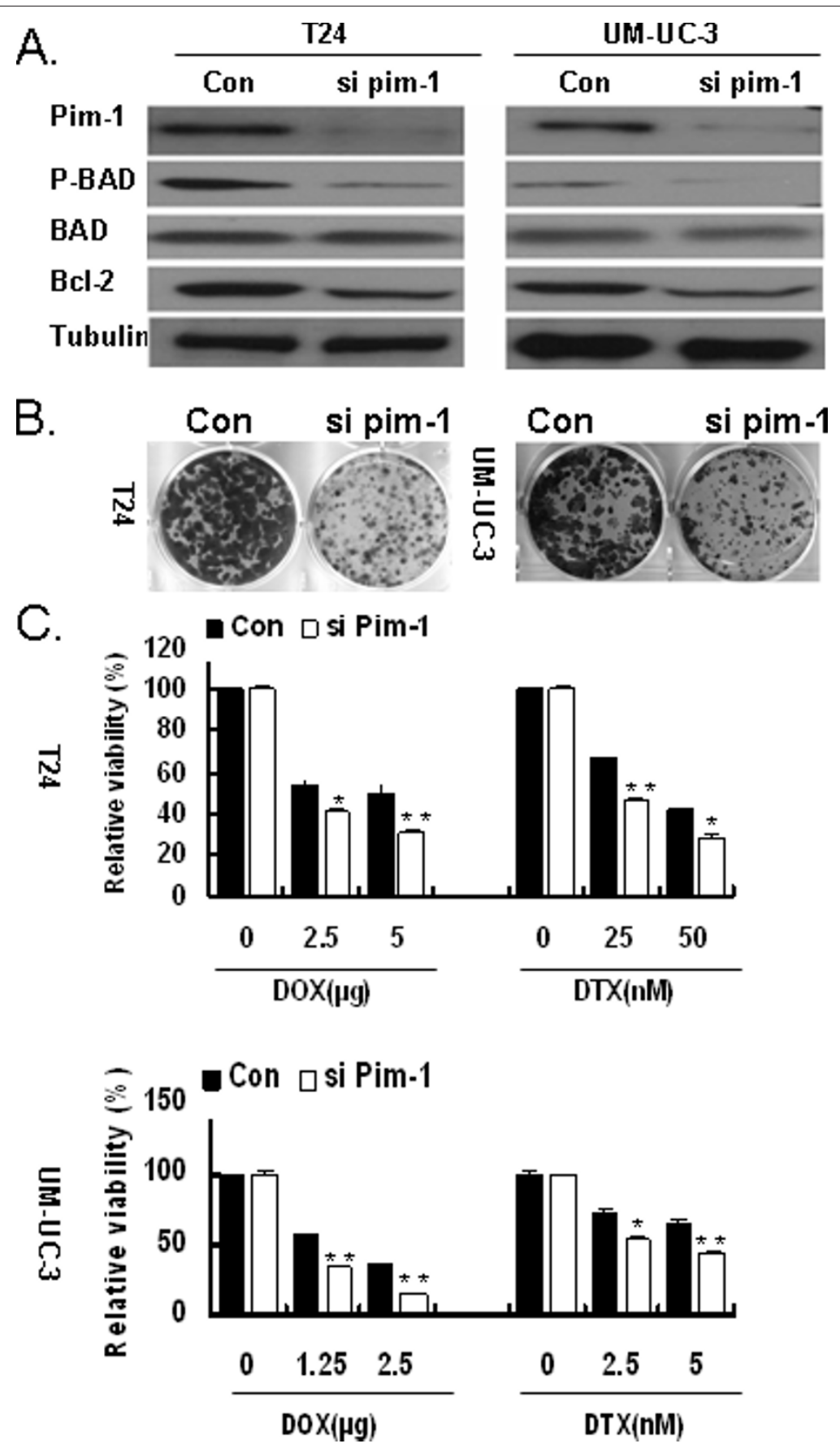

Figure 3 Downregulation of Pim-1 inhibited the bladder cells growth and sensitized them to Doxorubicin and Docetaxel treatment. A. Knockdown of Pim-1 decreased the phosphorylation of Bad and the expression of Bcl-2. The cells were infected lentivirus siRNA specific for Pim-1(si Pim-1) or vector control. At $48 \mathrm{~h}$ postinfection, cells were lysed and the lysates were subjected to western blot with indicated antibody. B. Downregulation of Pim-1 inhibited the bladder cancer cell growth. Total of $1 \times 10^{4}$ T24 and UM-UC-3 cells were plated in each well of a 6well plate and infected with lentivirus encoding Pim-1 siRNA or vector control siRNA. The cell culture was maintained in complete medium for two weeks. Finally, the cell colonies were visualized by Coomassie blue staining. C. Decreased expression of Pim-1 sensitized bladder cancer cells to Doxorubicin and Docetaxel treatment. The cells were plated on 96 wells and infected with lentivirus encoding Pim-1 siRNA or vector control

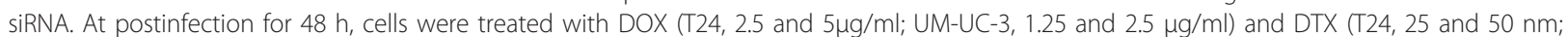
UM-UC-3, 2.5 and $5 \mathrm{~nm}$ ) for another $48 \mathrm{~h}$. The cell viability was assessed by WST-1 assay.*, $\mathrm{p}<0.05$ compared with the control; **, $\mathrm{p}<0.01$ compared with control. 
Overexpression of the Pim-1 protein has been reported in hematolymphoid malignancies and solid cancers $[4,5]$. Pim-1 has been asserted to promote tumorigenesis through multiple mechanisms, including its interaction with other proteins such as c-myc, p2 $7^{\mathrm{KIP} 1}, \mathrm{p} 21^{\mathrm{Cip} 1 / \mathrm{WAF} 1}$, Bad, Cdc25A/C dual specificity phosphates, androgen receptors and its ability to induce genomic instability [19-22]. The oncogenic effect of Pim-1 on non-haematopoietic malignancies is currently under investigation. Ellwood-Yen et al demonstrated that the overexpression of Pim-1, in cooperation with increased levels of c-myc, could lead to murine prostatic intraepithelial neoplasia and invasive adenocarcinoma in c-myc transgenic mice [23]. Taking into account the biological role of Pim-1 as an oncoprotein involved in cell cycle regulation and proliferative processes, our results suggested possible implication of Pim-1 in the initiation of bladder carcinogenesis. Moreover, upregulation of Pim-1 in invasive bladder cancer compared with Non-invasive tumors indicated that Pim-1 also may also contribute to bladder cancer progression.

Pim-1 has been considered as a survival kinase. Inhibition of Pim-1 results in a significant growth repression of prostate cancer cell [24]. Several inhibitors of Pim-1 have been shown to inhibit the growth of cancer cells, such as leukemic cells as well as prostate cancer cells. There are clinical trials to explore the safety of one of the Pim-1 inhibitor, SGI-1776, for the treatment of refractory nonHodgkin's lymphoma and prostate cancer $[25,26]$. It also has been demonstrated that Pim-1 monoclonal antibody (mAb) could induce apoptosis in cancers cells of the prostate, breast and colon. Furthermore, the inhibition of Pim-1 function by treatment with Pim-1 siRNA, Pim-1 inhibitors or Pim-1 mAb sensitizes cancer cells to chemotherapy [15,27-29]. It is noteworthy that Pim-1 interacted and phosphorylated Bad, Etk and BCRP leading to antagonism of drug-induced apoptosis $[14,17,18]$. In bladder cancer, after an initial transurethral resection of bladder tumor (TURBT), adjuvant intravesical therapy is another treatment strategy used to reduce the risk of recurrence. However, the cancer recurrence rate is still high and the recurring cancer cells can become more resistant to further intravesical chemotherapy. It is necessary to identify an effective strategy to counter act challenges associated with clinical management of bladder cancer patients. In this regard, Pim-1 might be one of the potential therapeutic targets for the treatment of bladder cancer and further studies examining Pim-1 as a target of therapeutics are worthy of investigation.

\section{Conclusions}

To the best of our knowledge, this is the first report showing overexpression of Pim-1 in bladder cancer and its association with bladder cancer cell survival, drug resistance and tumor progression. The current study offers significant information on the role and functions of Pim-1 in bladder cancer, and may aid in the development of novel therapy.

\section{Acknowledgements}

We would like to thank Dr Qiu (University of Maryland) for supplying the necessary experimental material (such as lentivirus of Pim-1 siRNA). This work was supported by grants from the National Natural Science Foundation(30872584); Guangdong Natural Science Foundation (8251008901000018); Doctoral Program of Guangdong Natural Science Foundation (9451008901002062), Preceptorial Program of Higher Education (20090171120062), Preceptorial Program of Sun Yat-Sen University (2009038) and International program fund of 985 project of Sun Yat-Sen University, China.

\section{Author details}

'Department of Urology, the First Affiliated Hospital, Sun Yat-Sen University, Guangzhou, 510080 China. ${ }^{2}$ School of Food Science and Nutrition, Leeds University, Leeds LS2 9JT, UK. ${ }^{3}$ Colleges of Light Industry and Food Sciences, South China University of Technology, Guangzhou, China. ${ }^{4}$ Department of Microbial Pathogenesis, Dental School, University of Maryland, Baltimore, MD-21201, USA.

\section{Authors' contributions}

XPM and $\mathrm{BH}$ evaluated the immunostainings. JXC and ZBX performed the statistical analysis. SJG and SPQ drafted the manuscript. JC revised the manuscript. All authors read and approved the final manuscript.

\section{Competing interests}

The authors declare that they have no competing interests.

Received: 12 November 2010 Accepted: 11 December 2010 Published: 11 December 2010

\section{References}

1. Epstein Jl, Amin MB, Reuter VR, Mostofi FK: The World Health Organization/International Society of Urological Pathology consensus classification of urothelial (transitional cell) neoplasms of the urinary bladder. Bladder Consensus Conference Committee. Am J Surg Pathol 1998, 22(12):1435-1448.

2. Edwards BK, Ward $E$, Kohler BA, et al: Annual report to the nation on the status of cancer, 1975-2006, featuring colorectal cancer trends and impact of interventions (risk factors, screening, and treatment) to reduce future rates. Cancer 2010, 116(3):544-573.

3. Jemal A, Siegel R, Xu J, Ward E: Cancer statistics 2010. CA Cancer J Clin 2010, 60(5):277-300.

4. Meeker TC, Nagarajan L, ar-Rushdi A, Croce CM: Cloning and characterization of the human PIM-1 gene: a putative oncogene related to the protein kinases. J Cell Biochem 1987, 35(2):105-112.

5. Dhanasekaran SM, Barrette TR, Ghosh D, et al: Delineation of prognostic biomarkers in prostate cancer. Nature 2001, 412(6849):822-826.

6. Chiang WF, Yen CY, Lin CN, et al: Up-regulation of a serine-threonine kinase proto-oncogene Pim-1 in oral squamous cell carcinoma. Int J Oral Maxillofac Surg 2006, 35(8):740-745.

7. Warnecke-Eberz $U$, Bollschweiler E, Drebber $U$, et al: Prognostic impact of protein overexpression of the proto-oncogene PIM-1 in gastric cancer. Anticancer Res 2009, 29(11):4451-4455.

8. Shah N, Pang B, Yeoh KG, et al: Potential roles for the PIM1 kinase in human cancer - a molecular and therapeutic appraisal. Eur J Cancer 2008, 44(15):2144-2151.

9. Mochizuki T, Kitanaka C, Noguchi K, Muramatsu T, Asai A, Kuchino Y: Physical and functional interactions between Pim-1 kinase and $\mathrm{Cdc} 25 \mathrm{~A}$ phosphatase. Implications for the Pim-1-mediated activation of the cMyc signaling pathway. J Biol Chem 1999, 274(26):18659-18666.

10. Bhattacharya N, Wang Z, Davitt C, McKenzie IF, Xing PX, Magnuson NS: Pim-1 associates with protein complexes necessary for mitosis. Chromosoma 2002, 111(2):80-95. 
11. Leverson JD, Koskinen PJ, Orrico FC, et al: Pim-1 kinase and p100 cooperate to enhance c-Myb activity. Mol Cell 1998, 2(4):417-425.

12. Lilly M, Sandholm J, Cooper JJ, Koskinen PJ, Kraft A: The PIM-1 serine kinase prolongs survival and inhibits apoptosis-related mitochondrial dysfunction in part through a bcl-2-dependent pathway. Oncogene 1999, 18(27):4022-4031.

13. Yan B, Zemskova M, Holder S, et al: The PIM-2 kinase phosphorylates BAD on serine 112 and reverses BAD-induced cell death. J Biol Chem 2003, 278(46):45358-45367.

14. Aho TL, Sandholm J, Peltola KJ, Mankonen HP, Lilly M, Koskinen PJ: Pim-1 kinase promotes inactivation of the pro-apoptotic Bad protein by phosphorylating it on the Ser112 gatekeeper site. FEBS Lett 2004, 571(13):43-49.

15. Kim O, Jiang T, Xie Y, Guo Z, Chen H, Qiu Y: Synergism of cytoplasmic kinases in IL6-induced ligand-independent activation of androgen receptor in prostate cancer cells. Oncogene 2004, 23(10):1838-1844

16. Cao KY, Mao XP, Wang DH, et al: High expression of PSM-E correlated with tumor grade in prostate cancer: a new alternatively spliced variant of prostate-specific membrane antigen. Prostate 2007, 67(16):1791-1800.

17. Xie $Y, X u$ K, Dai B, et al: The 44 kDa Pim-1 kinase directly interacts with tyrosine kinase Etk/BMX and protects human prostate cancer cells from apoptosis induced by chemotherapeutic drugs. Oncogene 2006, 25(1):70-78.

18. Xie Y, Xu K, Linn DE, et al: The 44-kDa Pim-1 kinase phosphorylates BCRP/ $A B C G 2$ and thereby promotes its multimerization and drug-resistant activity in human prostate cancer cells. J Biol Chem 2008, 283(6):3349-3356.

19. Zhang Y, Wang Z, Magnuson NS: Pim-1 kinase-dependent phosphorylation of p21Cip1/WAF1 regulates its stability and cellular localization in H1299 cells. Mol Cancer Res 2007, 5(9):909-922.

20. Morishita D, Katayama R, Sekimizu K, Tsuruo T, Fujita N: Pim kinases promote cell cycle progression by phosphorylating and down-regulating p27Kip1 at the transcriptional and posttranscriptional levels. Cancer Res 2008, 68(13):5076-5085.

21. Bachmann M, Kosan C, Xing PX, Montenarh M, Hoffmann I, Moroy T: The oncogenic serine/threonine kinase Pim-1 directly phosphorylates and activates the G2/M specific phosphatase Cdc25C. Int I Biochem Cell Biol 2006, 38(3):430-443.

22. Wang J, Kim J, Roh M, et al: Pim1 kinase synergizes with c-MYC to induce advanced prostate carcinoma. Oncogene 2010, 29(17):2477-2487.

23. Ellwood-Yen K, Graeber TG, Wongvipat J, et al: Myc-driven murine prostate cancer shares molecular features with human prostate tumors. Cancer Cell 2003, 4(3):223-238.

24. Zhang T, Zhang X, Ding K, Yang K, Zhang Z, Xu Y: PIM-1 gene RNA interference induces growth inhibition and apoptosis of prostate cancer cells and suppresses tumor progression in vivo. J Surg Oncol 2010, 101(6):513-519.

25. Chen LS, Redkar S, Bearss D, Wierda WG, Gandhi V: Pim kinase inhibitor, SGI-1776, induces apoptosis in chronic lymphocytic leukemia cells. Blood 2009, 114(19):4150-4157.

26. Mumenthaler SM, Ng PY, Hodge A, et al: Pharmacologic inhibition of Pim kinases alters prostate cancer cell growth and resensitizes chemoresistant cells to taxanes. Mol Cancer Ther 2009, 8(10):2882-2893.

27. Li J, Hu XF, Xing PX: Pim-1 expression and monoclonal antibody targeting in human leukemia cell lines. Exp Hematol 2009, 37(11):1284-1294.

28. Hu XF, Li J, Vandervalk S, Wang Z, Magnuson NS, Xing PX: PIM-1-specific mAb suppresses human and mouse tumor growth by decreasing PIM-1 levels, reducing Akt phosphorylation, and activating apoptosis. J Clin Invest 2009, 119(2):362-375.

29. Teh BG: [Pim-1 induced by hypoxia is involved in drug resistance and tumorigenesis of solid tumor cells]. Hokkaido Igaku Zasshi 2004, 79(1):19-26.

doi:10.1186/1756-9966-29-161

Cite this article as: Guo et al: Overexpression of Pim-1 in bladder cancer. Journal of Experimental \& Clinical Cancer Research 2010 29:161.

\section{Submit your next manuscript to BioMed Central and take full advantage of:}

- Convenient online submission

- Thorough peer review

- No space constraints or color figure charges

- Immediate publication on acceptance

- Inclusion in PubMed, CAS, Scopus and Google Scholar

- Research which is freely available for redistribution

Submit your manuscript at www.biomedcentral.com/submit 